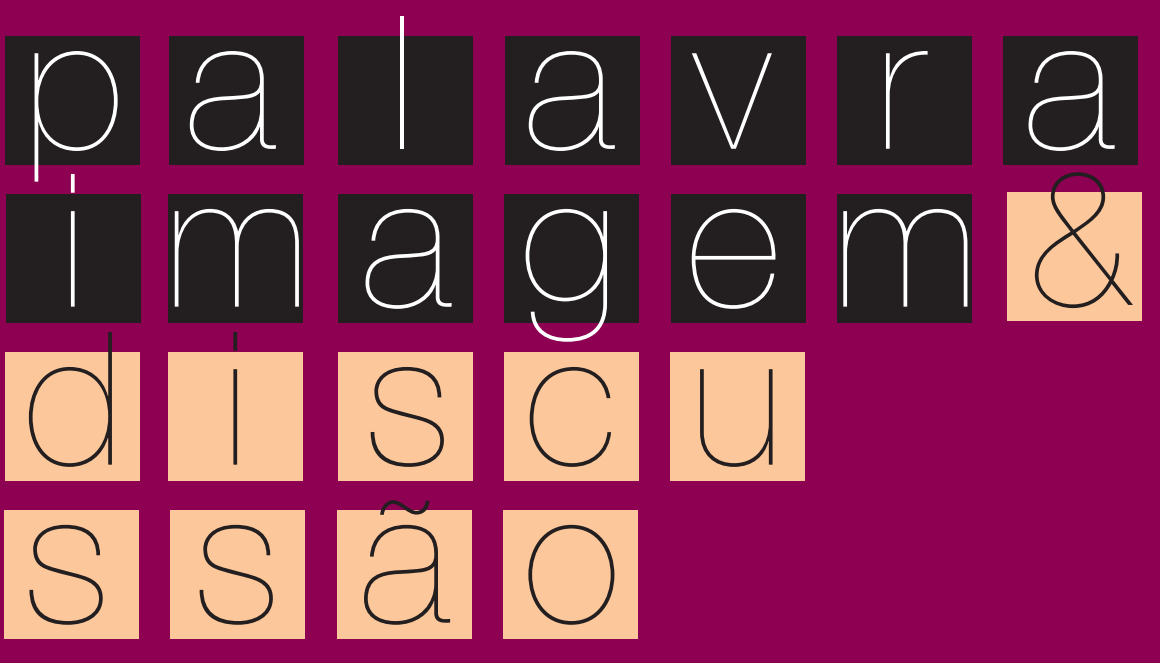




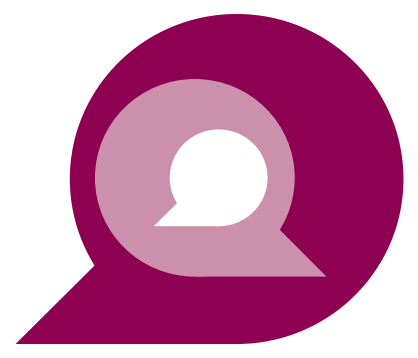




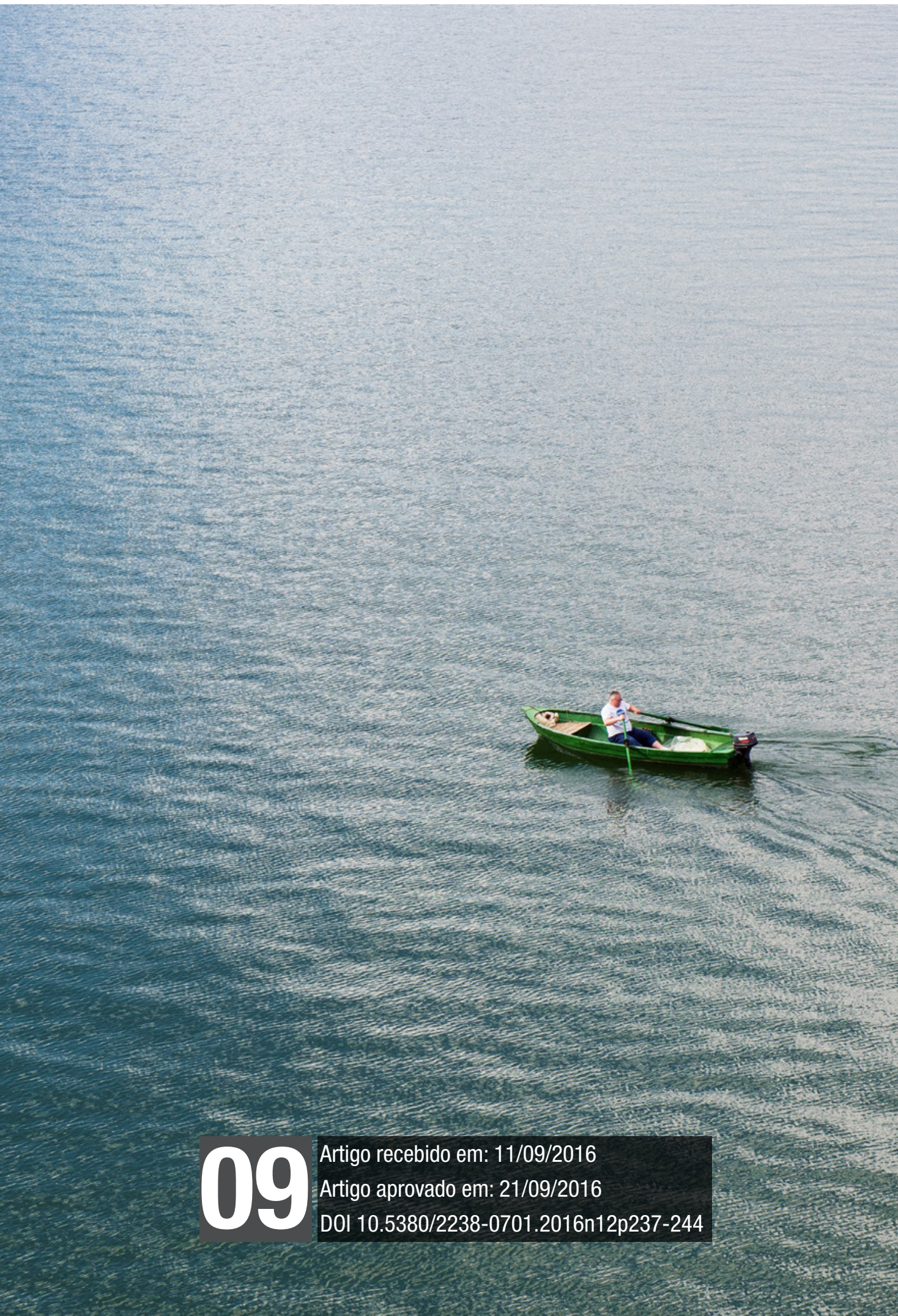


Análise sistêmica. Percursos de uma investigadora.

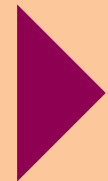




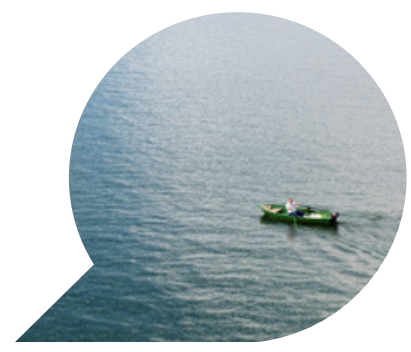

\section{Da análise sistêmica à produção de uma teoria geral: percursos de uma investigadora implicada ${ }^{1}$}

De l'analyse systémique à la production d’une théorie générale : parcours d'une chercheure impliquée

From a systemic analysis to the conception of a general theory: following the path of a truly involved researcher

FRANÇOISE THIBAULT ${ }^{2}$

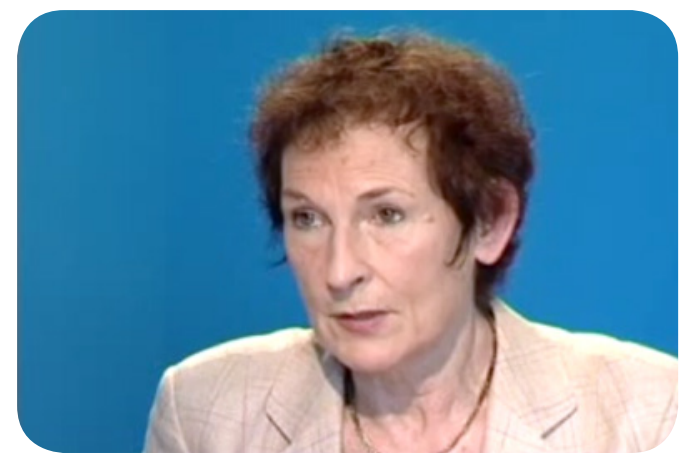

Imagem - Fotografia extraída da entrevista de 2006

Fonte: http://www.canal-u.tv/video/canal_tematice/entretien_avec_genevieve_jacquinot.3591

1 Tradução de Lia Raquel Oliveira

2 FMSH, Paris, francoise.thibault4@orange.fr 


\section{Introdução}

É para nós uma felicidade que a rede permita que se veja e ouça o belo percurso daquela que declara, após mais de quarenta anos de trabalho sobre as tecnologias para a educação: "o estatuto da imagem é o tema essencial da minha investigação". Sem dúvida, mas ao ouvirmos Geneviève Jacquinot, o que retemos é também o laço indefectível que ela criou entre as suas investigações e o seu empenhamento pessoal nos sistemas educativos e universitários.

A entrevista que realizamos com Jacques Wallet ${ }^{3}$, no dia 4 de outubro de 2006, no quadro do programa imaginado com Georges -Louis Baron: "Memórias das TICs" constitui um rico testemunho desse empenho.

\section{Os quadros do empenhamento}

Invocar a implicação do investigador, em ciências humanas e sociais, é, geralmente, fazer referência a uma das diferentes correntes da "investigação-ação" e aos seus métodos de investigação da vida em sociedade. A metodologia não é nova e foi desenvolvida, desde os anos 1930, nos Estados Unidos, no quadro da primeira Escola de Chicago. A "sociologia clínica” que é ali praticada centra-se na pessoa individual em dificuldade e induz, por parte do investigador, uma implicação pessoal, um sentimento de empatia face aos problemas encontrados pelos atores e, até, a procura de soluções.

Não evocaremos aqui a longa lista de abordagens e métodos desenvolvidos até aos anos 1980 em muitos países e continentes na esfera da "investigação-ação" ou da "intervenção" (América do Sul, à volta de Paulo Freire, Danilo Dolci em Itália, Kurt Lewin nos Estados Unidos...). A vida urbana e as coabitações entre os grupos sociais são os temas mais estudados nessa época. É nos anos 1960 e 1970 que o tema da educação se torna central nas práticas científicas que reclamam para si a intervenção. Os sociólogos trabalham com psicólogos e psicanalistas, cada vez mais presentes no domínio das Ciências Sociais e Humanas. Os investigadores intervencionistas passam a pertencer às correntes da pedagogia institucional, da psicoterapia institucional ou ainda à corrente da intervenção psicossociológica.

Apesar de insistir na ligação entre a investigação e a ação que

3 http://www.canal-u.tv/video/canal_tematice/entretien_avec_genevieve_jacquinot.3591 
nunca deixou de cultivar ao longo da sua carreira, na sua entrevista, Geneviève Jacquinot faz referência a um quadro e a uma personalidade completamente diferentes: Etienne Brunswic, que se empenhou, sobretudo, no desenvolvimento de programas de televisão educativa na África francófona. Encontro entre reflexões pedagógicas e uma grande visão para a educação, a abordagem sistêmica comentada e exposta por E. Brunswic radica na convicção de que os "países do terceiro mundo", pouco organizados, podem ser o campo de experimentações arrojadas, fonte de novos modelos educativos. Não raras vezes citada, a segunda edição do livro de 1981 faz com que se esqueça de que "L’Éducateur et l'approche systémique, Manuel pour améliorer la pratique de léducation dans les pays en voie de développement" foi editado pelas Presses de l'Unesco em 1976. Com efeito, esta obra é a tradução francesa de um estudo realizado a pedido da Unesco, por três personalidades de países do "Terceiro e do Quarto mundo": Taju Balogun, da Nigéria, Shirad Kulharni, da Índia e Seti Jadi, da Indonésia, todos implicados em projetos educativos. Charles Blake assumiu a redação final da versão inglesa. Guy Berger e Etienne Brunswic, este último secretário da Comissão francesa junto da Unesco, traduziram e adaptaram o manual original. Pode ver-se nesta configuração a prefiguração de um fenômeno que acabará por se estender a inúmeros setores, a partir do início dos anos 1980: o recurso a peritos (meio sábio, meio homem de ação) para fazer com que as organizações atuem.

Reivindicado enquanto produto da reflexão de profissionais experientes, o conceito de análise sistêmica apresentado por Manuel pour améliorer la pratique de l'éducation dans les pays en voie de développement corresponde ao estudo racional de um problema, isto é, à procura de soluções para adaptar os meios de que dispomos aos fins visados. Assenta na elucidação de um conjunto de questões e na consideração de uma multiplicidade de parâmetros. As questões são simples: quais são os objetivos que determinado sistema de ensino quer alcançar? De que meios dispomos, concretamente, para atingir esses objetivos? Quais os múltiplos constrangimentos externos que vão favorecer ou prejudicar os esforços a desenvolver? Quem são os múltiplos decisores que intervêm no problema em causa e qual o raio de ação de cada um deles?

A análise sistêmica pressupõe a elaboração de estratégias de ações, isto é, de combinações apropriadas, e devidamente organizadas 
no tempo, dos meios escolhidos de entre os disponíveis, para concretizar as finalidades propostas. Produto da reflexão e da observação de especialistas, a análise sistêmica destina-se prioritariamente a profissionais. Este projeto está bem explícito no prefácio da edição de 1981:

Este manual apresenta ao leitor uma técnica, geralmente conhecida por abordagem sistêmica, que permite analisar situações educativas práticas, com vista a melhorar a eficácia do processo de ensino ou de aprendizagem. Tem por objeto ajudar todos aqueles que exercem atividades educativas (docentes, diretores de estabelecimento, documentalistas, formadores de adultos, animadores de coletividades, agentes de desenvolvimento, especialistas em métodos e técnicas, administradores, inspetores, etc.) a identificar os pontos fortes e os pontos fracos das situações pedagógicas com as quais são confrontados e a nelas introduzir as modificações que estão ao seu alcance, tendo em conta o nível de decisão em que estão colocados. [...] Poder-se-á esperar que o leitor aprenda, assim, a decompor uma situação educativa nos seus elementos constitutivos e, sobretudo, a determinar aqueles sobre os quais pode atuar [...]. Finalmente, o leitor deverá ser capaz de conceber e de operacionalizar mudanças, isto é, introduzir inovações suscetíveis de modernizar o sistema educativo em causa. [...] (JACQUINOT, 2006)

A fidelidade de Geneviève Jacquinot à abordagem sistémica assume, em 2006, uma dimensão muito particular. Com efeito, numa época em que a ciência dispõe de uma espécie de monopólio do pensamento, referir-se a uma prática que se posiciona claramente como um método e não como uma ciência releva de muita originalidade, senão de algum atrevimento.

(a abordagem sistêmica) não é uma ciência, nem tão pouco uma conceção particular dos fatos educativos e sociais. O seu objetivo é permitir a todos aqueles que trabalham numa situação complexa, e quaisquer que sejam os papéis desenvolvidos, analisar essa complexidade, descrevê-la, identificar, se as houver, as suas disfunções, tomar em consideração os diferentes níveis da realidade social ou institucional. Além disso, esforça-se por possibilitar àquele que intervém controlar, tanto quanto possível, as transformações em cadeia que ele determina e avaliar as consequências das mesmas. (BRUNSWIC, 1981, p. 10)

Ao dotar a ciência das qualidades necessárias ao exercício da reflexividade do especialista, é a prática que Geneviève Jacquinot 
coloca no centro das suas preocupações e, contrariamente a muitos discursos sobre a educação, o argumento científico não está ali para justificar a prática, mas para alimentá-la. Embora a autora de Image et pédagogie lembre, no início desta entrevista, que, ao contrário de muitos audiovisualistas, ela não passou pela célebre formação da École Normale Supérieure de Saint Cloud, ela assume-se como uma boa representante da mesma, formada na escola da vida, ensinando e participando na realização de filmes educativos com realizadores como Almendros ou Éric Robert. Personalidade integrando um grupo informal que se reconhece nas "tecnologias educativas", precisa, como diz, "de se distanciar através da investigação", mas também de ser capaz de conceber um produto pedagógico para otimizar as utilizações dos alunos.

O empenhamento no terreno é, assim, central. Nos anos 1960 e 1970, Geneviève Jacquinot intervém em experiências que marcaram o seu tempo, ao nível do ensino primário e do secundário: o colégio experimental de Marly-le-Roi e a televisão escolar na Costa do Marfim. Acompanha inúmeros programas de educação através da televisão no estrangeiro. Convicta de que é necessário passar pela experiência dos media para compreender os fenômenos em jogo no ensino através dos media, participa, logicamente, na experiência de Paris 8-Vincennes. Cooptada como assistente, defende aí a ideia de que uma aprendizagem da imagem através da imagem é necessária na formação dos espíritos que participa da democratização da sociedade.

O que é que estas experiências lhe ensinam?

Que os próprios pioneiros podem estar divididos: é a luta estéril dos anos 1980, entre os defensores da "educação para a imagem" e os defensores da "educação através da imagem". Que o trabalho em equipe é um fator-chave para os docentes e para os alunos, é a grande prova de Marly. Que o recurso educativo, ainda que de elevada qualidade, não regula a questão da aprendizagem. Que o desprezo pela técnica e pelo suporte é poderoso e tem diversas origens: os defensores das disciplinas em nome do saber a transmitir; a hierarquia educativa que prefere um docente sozinho perante a sua turma a um docente integrado numa equipe (em Marly, os inspetores tiveram de inspecionar equipes de docentes, mas depressa retomaram a inspeção individual); uma parte dos docentes da esquerda libertária que rejeita os media (o estudo de Vincennes será, em parte, destruído em nome da luta contra os meios de comunicação de massa, instrumen- 
tos de um poder central). Que a instituição não está pronta a transformar-se e que estamos longe da sua generalização.

As interrogações que Geneviève Jacquinot formula acerca destas experiências, que tiveram momentos de glória, mas foram inconsequentes, conduzem-na para a análise sistêmica. Para ela, a generalização pressupõe o domínio do conjunto dos níveis. Os pioneiros não conseguiram "controlar todos os níveis". Daí o fracasso das experiências.

$\mathrm{O}$ assunto poderia ser encerrado, ficando a pioneira apenas dececionada. Porém, a pioneira gosta dos "princípios" e dos "caminhos difíceis", como em Marly. Vê na informática e, sobretudo, na internet a força de uma pressão social que vai obrigar a instituição escolar e universitária a incitar uma reforma. Os níveis poderiam, quase per se, embarcar em transformações profundas, até então tornadas impossíveis. Era chegado o momento da produção de uma "teoria global" que articulasse o ensino da semiologia, da psicologia cognitiva e da teoria dos usos. Para Geneviève Jacquinot, se dispomos de tijolos, é necessário uma teoria da construção no seu conjunto. Belo programa, aquele que nos propõe a grande senhora da "imagem pedagógica".

\section{REFERÊNCIAS}

BERGER, G.; BRUNSWIC, E. Léducateur et l'approche systémique Manuel pour améliorer la pratique de l'éducation. Unesco: Paris, 1981.

JACQUINOT, G. Image et pédagogie. Analyse sémiologique du film à intention didactique. (préface de Christian Metz). Paris: PUF.

LEWIN, K. Psychologie dynamique. Les relations humaines. Introduction, Morceaux choisis et présentés par Claude Faucheux. Traduction par M. et C. Faucheux. Révision générale par J.-M. Lemaine. Paris: Presses Universitaires de France, 1959. 